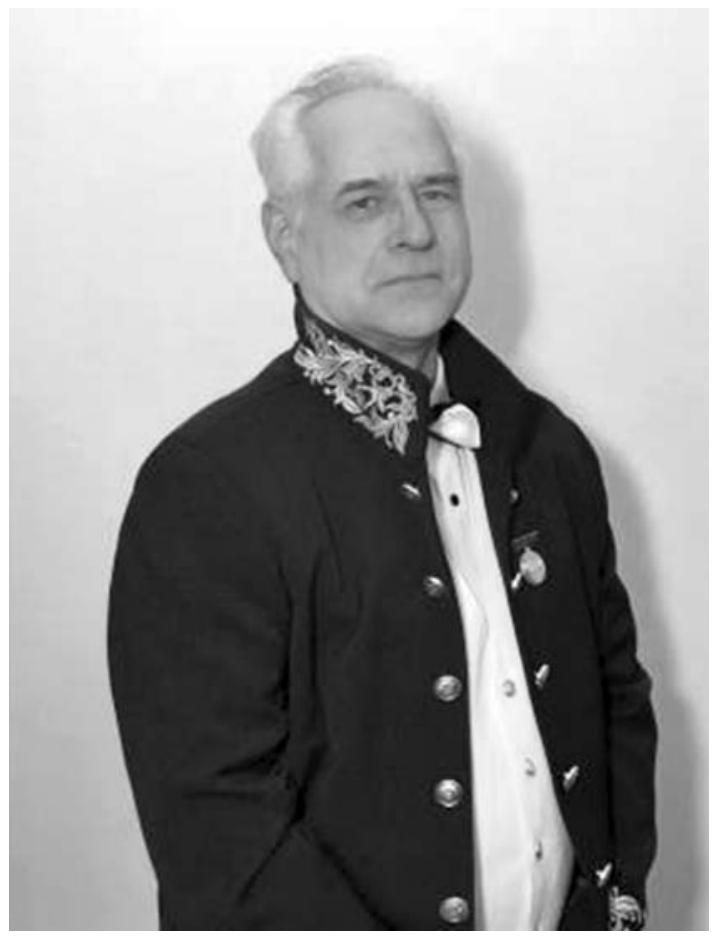

(20.12.1940 - 23.03.2015)

\title{
IN MEMORY OF ACADEMICIAN OF ACADEMY OF SCIENCES OF MOLDOVA PROFESSOR CONSTANTIN TURTA
}

Academician Constantin Turta, Doctor habilitate in chemistry, Professor, famous scientist, world-renowned chemist, Laureate of the State Prize of the Republic of Moldova, person of a exquisite culture and noble attitude, was born on December $20^{\text {th }} 1940$ in the village Buciusca, district of Rezina. After graduating the secondary school No.1 from town Rezina in 1956, he has successfully passed the entrance examinations, becoming a student of Faculty of Chemistry of State University of Chisinau. After graduating university in 1961, he is employed, as a researcher, in a military institute of Ministry of Defense of U.S.S.R. in the Saratov region, solving the problems of sorption and filtering substances. After 3 years, in 1964, he returns to Moldova, being employed as assistant at Department of General and Inorganic Chemistry at Polytechnic Institute of Chisinau.

In 1966 he enrolled in doctoral studies at the Institute of Chemistry of the A.S.M. and was delegated to pursue doctoral studies at the Institute of Physical Chemistry of A.S. U.S.S.R. (Moscow), where he works until April 1970. He has successfully presented his PhD thesis entitled "Studies of coordination compounds of iron with organic ligands by Mössbauer method” in 1971. At the Institute of Chemistry of A.S.M. he passed all scientific steps - from researcher to the head of laboratory.

Scientist Constantin Turta was a worldwide specialist in the field of bioinorganic and coordination chemistry. He became known in the scientific community by his fundamental pioneering work on the application of Mössbauer spectroscopy in inorganic and coordination chemistry.

Professor Turta developed the chemistry of homo- and heteropolynuclear clusters of iron (III), which allowed drafting new synthetic methods and preparing new physiologically active substances. A high appreciation have his works that are devoted to the synthesis and characterization of mixed valence iron (III) complexes, description of the dynamic phenomena, including dynamics of electron density in space and time, phase transition, elucidation of the factors influencing transition temperature and type of spin crossover, as well as the speed of electron transfer in the studied systems. 
On the basis of Mössbauer spectroscopy a new method was developed and a class of substances was proposed to study the intermolecular electron transfer process.

International acknowledgment of founded by academician Constantin Turta scientific school is based on the polyvalent character of research, modern approach and argued presentation of conclusions, as well as well-documented elaborations and achievement of various projects within NATO, INTAS, CRDF, SCOPES, FP7 programs.

In the late 80s of last century Constantin Turta became recognized as a scholar of the highest authority in the application of Mössbauer spectroscopy in inorganic and coordination chemistry, as it was mentioned during the discussion of his habilitate thesis entitled "Dynamic effects in mono- and polynuclear complexes of iron with polydentate ligands (synthesis, structure, Mössbauer spectra and magnetic properties)” in the Institute of Physical Chemistry of A.S.U., Kiev, Ukraine.

In 1995 Mr. Constantin Turta was given the title of professor and elected as a corresponding member of A.S.M., subsequently becoming a titular member of A.S.M. (2010).

Due to steadiness and depth in the realization of scientific researches, scientific successes, but also his intelligence and verticality, authority of academician Constantin Turta in society had become emblematic, that is why his election in 2000 as general scientific secretary of A.S.M. was met as natural and necessary act.

Academician Constantin Turta is the author of over 550 scientific publications, including 200 published in prestigious international journals, 35 patents and a university handbook "Introduction to gamma resonance spectroscopy (Mössbauer spectroscopy).”

Professor Turta not only has lectured in universities from our country - Technical University, State University of Moldova, University of A.S.M., but also abroad, e.g. University “Gh. Asachi”, Iasi, Romania; University of Tajikistan, Dushanbe; West University of Timisoara, Romania etc.

Under the tutorship of academician Constantin Turta $13 \mathrm{PhD}$ and 2 Dr. habilitate theses were prepared and successfully discussed. He has actively contributed to the works of many international scientific forums with plenary communications and was one of the organizers, and from 2006 - President of Organizing Committee of the International Conference "Physical Methods in Coordination and Supramolecular Chemistry" that takes place every three years in Chisinau, and has a high visibility among scientists.

Merits of academician Constantin Turta were appreciated both by the scientific community and the government. He is Laureate of the State Prize of the Republic of Moldova, Knight of the Order "Labour Glory" and Medal "Dimitrie Cantemir" of the Academy of Sciences of Moldova.

Corresponding member Tudor Lupascu, Director of the Institute of Chemistry of Academy of Sciences of Moldova

Dr. habilitate Aculina Aricu, Vice-director of the Institute of Chemistry of Academy of Sciences of Moldova 